\title{
Applications of Grey Relational Analysis to Enterprise Performance Evaluation of Express Listed Companies in China
}

\author{
Baojia Xue ${ }^{1, a}$, Mingfei Liu ${ }^{1, b}$ and Qian Sun ${ }^{1, c}$ \\ ${ }^{1}$ School of Management, Wuhan University of Technology, Wuhan, P.R.China, 430070 \\ a1635831276@qq.com, bliumingfei@163.com, c1812289913@qq.com
}

\begin{abstract}
Keywords: Express, Enterprise Performance, Analytic Hierarchy Process (AHP), Grey Relational Analysis (GRA)

Abstract. Performance evaluation of listed companies can not only display current operating conditions of enterprises, but also reflect future direction of optimization of listed companies. To find a simple, reasonable and effective express listed enterprise performance evaluation method is particularly important. In this paper, we use all four express listed companies in main business of delivery logistics in Chinese stock market as samples, and a multilevel grey comprehensive evaluation model is proposed to construct an evaluation index system with 1 target, 3 categories, 11 indicators including index grading and weighting. Then by grey relational analysis, we obtain grey relational degree and comprehensive performance ranking, and find that STO had the best enterprise performance, and the innovative performance of SF Holding was highlight in the four express listed enterprises in 2016.
\end{abstract}

\section{Introduction}

In recent years, express service has penetrated quickly into numerous businesses and families in China. Express service refers to receive, transport, deliver separate packaged, addressable express items or other items without storage, which are delivered to the recipient or designated location at the commitment time limit, and get the receipt of delivery service. Since 2016, a number of domestic courier companies have listed, such as YTO, STO, ZTO Express, SF Holding, YUNDA Corp and BSTI Express. The capital advantage of express listed enterprise has promoted the employment level of country and played an important role in the economic upgrading and transformation. Express service has become a new highlight in China's economic development, and its performance is directly related to the development of express industry. Then to find a simple, reasonable and effective express listed enterprise performance evaluation method is particularly important.

Stanley E. Seashore first put forward the classification of enterprise performance evaluation standards in 1960s, the various aspects of organizational performance were studied in a comprehensive way, and made an understanding of the relationship between them and their relative importance. Since 1990s, domestic scholars had begun to pay attention to enterprise performance evaluation, and some management research institutions had also carried out many useful explorations. In terms of express enterprise performance evaluation, Liu Jingzhi et al. (2006) proposed a bench marking method to measure express enterprise performance, taking the bench marking method implemented by Holland TNT Express as an example, this paper studied the application model of bench marking in express enterprise performance evaluation in China[1]. Liu Ying and Mao Cuiyun (2014) used fuzzy comprehensive evaluation method to evaluate four enterprise performance indicators, such as financial dimension, customer dimension, internal process, learning and growth, it was found that the overall express enterprise performance was at a general level, and internal process was better than the other three indicators. It showed that it paid more attention to the internal process management and improvement[2].

For listed company performance is influenced by many factors, and these factors interact with each other, it is rather difficult to describe listed company performance and performance level precisely and accurately. Grey relational analysis has emerged in recent years as a new tool to deal with problems of small samples and insufficient information. It has obvious theoretical analysis advantage 
for the small sample system with inaccurate and incomplete information. In the multilevel grey comprehensive evaluation model, the weights of each level index are determined by analytic hierarchy process, and some index information of enterprise performance system can be used to evaluate performance and laws of the overall system based on grey relational analysis. In summary, this paper chose all four currently domestic listed express enterprises, such as YTO, STO, SF Holding and YUNDA Corp, using the multilevel grey comprehensive evaluation model to evaluate the performance of those four express listed enterprises in 2016.

\section{Listed enterprise performance evaluation index system}

At present, China Chenxin Securities Rating Co., Ltd. is a evaluation institution of enjoying high reputation in domestic listed company performance evaluation method research. The company, in cooperation with the Journal of China Securities, annually evaluates the operating performance of listed companies.The evaluation method is based on the relevant information disclosure of listed companies, the listed companies through the rate of return on net assets, total assets growth rate, total profit growth rate, debt ratio, liquidity ratio and total capital ratio of 6 indicators for assessment, and then according to the importance of each indicator to determine the weight of each index in the comprehensive the evaluation. In this method, the final score of each company is in the output of each single index assessment score multiplied by the weight of each indicator, and then summed up.

Considering from the industry characteristics, express logistics enterprise external take the risk of market competition environment and society, the internal bearing the risk of its own products, personnel, assets. Therefore, an accurate evaluation of enterprise performance can avoid social risk, effectively use social resources and its own resources to ensure the good operation and profitability of the enterprise, and enhance enterprise performance level. Refer to the above literature and appraisal institutions related indicators, this paper is based on financial indicators, combined with the logistics characteristics of the listed companies, respectively select related indexes from the enterprise operating performance, social performance and innovation performance. The concrete index system as shown in Table 1:

Table 1 Performance Evaluation Index System of Express Listed Enterprise

\begin{tabular}{ccc}
\hline First level index & Two level index & Three level index \\
\hline & & Return on equity $C_{1}$ \\
& & The total return on assets $C_{2}$ \\
& Operational & Main business profit margins $C_{3}$ \\
Enterprise & performance $B_{1}$ & Cost margins $C_{4}$ \\
performance $A$ & & Total asset turnover $C_{5}$ \\
& & Shareholders' equity ratio $C_{6}$ \\
& & Current ratio $C_{7}$ \\
& Social performance $B_{2}$ & Dividend financing ratio $C_{8}$ \\
& Innovation & Dividend yield $C_{9}$ \\
& performance $B_{3}$ & Ratio of income tax to total profit $C_{10}$ \\
& & $C_{11}$ \\
\hline
\end{tabular}

\section{Listed enterprise performance evaluation model}

We are based on the principle and method of multilevel grey comprehensive evaluation, to build the express listed enterprise performance evaluation model. It is assumed that i listed companies should be evaluated by $\mathrm{k}$ indexes, which of corresponding weights should be calculated by Analytic Hierarchy Process.It is a method to compare the importance of each element in the same level, construct a comparison judgment matrix, and ultimately calculate the synthetic weights of each layer element to the system target. 
General speaking, the evaluation indexes usually have different dimension and magnitude, so they can not be compared directly. In order to ensure the reliability of the results, it is necessary to standardize the original indexes.

First of all, according to the selected indicators to determine the optimal index vector $F^{*}=\left[x_{1}^{*}, x_{2}^{*}\right.$, $\left.x_{3}^{*}, \ldots, x_{k}^{*}\right]$, the combination of the best value vector and the enterprise performance index matrix constitutes the sample space of grey enterprise performance evaluation:

$$
\left[\begin{array}{ccccc}
x_{1}^{*} & x_{2}^{*} & x_{3}^{*} & \mathrm{~K} & x_{k}^{*} \\
x_{1}^{1} & x_{2}^{1} & x_{3}^{1} & \mathrm{~K} & x_{k}^{1} \\
x_{1}^{2} & x_{2}^{2} & x_{3}^{2} & \mathrm{~K} & x_{k}^{2} \\
\mathrm{M} & \mathrm{M} & \mathrm{M} & \mathrm{M} & \mathrm{M} \\
x_{1}^{i} & x_{2}^{i} & x_{3}^{i} & \mathrm{~K} & x_{k}^{\mathrm{i}}
\end{array}\right]
$$

Secondly, based on the grey system theory, $\left\{x^{*}\right\}=\left[x_{1}^{*}, x_{2}^{*}, x_{3}^{*}, \ldots, x_{k}^{*}\right]$ is used as the reference sequence, $\left\{x^{i}\right\}=\left[x_{1}^{i}, x_{2}^{i}, x_{3}^{i}, \ldots, x_{k}^{i}\right]$ is used as the comparative sequence, to calculate grey relational coefficient $\xi_{i}(k)$ of each index and the optimal index.

$$
\xi_{i}(k)=\frac{\frac{\min }{i} \frac{\min }{k}\left|x_{k}^{*}-x_{k}^{i}\right|+\rho \frac{\max }{i} \frac{\max }{k}\left|x_{k}^{*}-x_{k}^{i}\right|}{\left|x_{k}^{*}-x_{k}^{i}\right|+\rho \frac{\max }{i} \frac{\max }{k}\left|x_{k}^{*}-x_{k}^{i}\right|} .
$$

In Eq. 1, $\rho \in[0,1]$, generally to take $\rho=0.5$.

Finally, the results of comprehensive evaluation are analyzed:

$$
r_{i}=\sum_{k=1}^{n} W(k) \times \xi_{i}(k)
$$

If weighted relational degree ${ }^{r_{i}}$ is the largest, it shows that listed enterprise performance $i$ is the best, and the order of listed enterprise performance can be ranked accordingly.

\section{Empirical analysis}

Our research objects are four express listed companies using main delivery logistics in Chinese stock market. They are YTO, STO, SF Holding, YUNDA Corp, respectively, expressed as $V_{1}, V_{2}, V_{3}, V_{4}$. The data in this paper are derived from annual report of listed companies. According to above evaluation model, comprehensive assessment process of express enterprise performance is as follows:

\section{About the weight of each indicator}

This paper use AHP to determine the weight of each index. By the nine-scale method, experts compare the importance of each indicator element, and construct a judgment matrix to determine the weight of each index. The results are shown in Tables 2-3. Table 2 indicates that the weight of each performance is followed by operational performance (0.778), social performance (0.111), and innovation performance (0.111). Thus, we get ultimate weights of operational performance factors as shown in Table 3. 
Table 2 the Weights of the Two Level Index Dimension

\begin{tabular}{c|cccc}
\hline$A$ & $B_{1}$ & $B_{2}$ & $B_{3}$ & W \\
\hline$B_{1}$ & 1 & - & - & 0.778 \\
$B_{2}$ & $1 / 7$ & 1 & - & 0.111 \\
$B_{3}$ & $1 / 7$ & 1 & 1 & 0.111 \\
\hline
\end{tabular}

$* \lambda \max =3, \quad \mathrm{CI}=0, \mathrm{RI}=0.58, \mathrm{CR}=0<0.1$

Table 3 the Weights of the Three Level Index Dimension of Operational Performance

\begin{tabular}{l|ccccccccccc}
\hline$B_{1}$ & $C_{1}$ & $C_{2}$ & $C_{3}$ & $C_{4}$ & $C_{5}$ & $C_{6}$ & $C_{7}$ & $C_{8}$ & $C_{9}$ & $\mathrm{w}$ & $\mathrm{u}$ \\
\hline$C_{1}$ & 1 & - & - & - & - & - & - & - & - & 0.154 & 0.120 \\
$C_{2}$ & 1 & 1 & - & - & - & - & - & - & - & 0.154 & 0.120 \\
$C_{3}$ & 1 & 1 & 1 & - & - & - & - & - & - & 0.154 & 0.120 \\
$C_{4}$ & $1 / 2$ & $1 / 2$ & $1 / 2$ & 1 & - & - & - & - & - & 0.077 & 0.060 \\
$C_{5}$ & $1 / 2$ & $1 / 2$ & $1 / 2$ & 1 & 1 & - & - & - & - & 0.077 & 0.060 \\
$C_{6}$ & $1 / 4$ & $1 / 4$ & $1 / 4$ & $1 / 2$ & $1 / 2$ & 1 & - & - & - & 0.038 & 0.030 \\
$C_{7}$ & $1 / 4$ & $1 / 4$ & $1 / 4$ & $1 / 2$ & $1 / 2$ & 1 & 1 & - & - & 0.038 & 0.030 \\
$C_{8}$ & 1 & 1 & 1 & 2 & 2 & 4 & 4 & 1 & - & 0.154 & 0.120 \\
$C_{9}$ & 1 & 1 & 1 & 2 & 2 & 4 & 4 & 1 & 1 & 0.154 & 0.120 \\
\hline
\end{tabular}

$* \lambda \max =9, \quad \mathrm{CI}=0, \mathrm{RI}=1.45, \mathrm{CR}=0<0.1$

To sum up, the weight of each index of express listed enterprise performance is: $w(11)=(0.120,0.120,0.120,0.060,0.060,0.030,0.030,0.120,0.120,0.111,0.111)$.

\section{Index calculation method}

We does not need to carry on the dimensionless processing to the index, because original data of each index are percentage. The higher evaluation index value, the better enterprise performance. Therefore, we take maximum value as the optimal value in the selected metric. Their grey relational coefficients may be computed using Eq. 1. The results are shown in Table 4. Thus, we use Eq. 2 to calculate weighted relational degrees and the results are summarized in Table 5.

Table 4 Grey Relational Coefficients of Express Listed Enterprises Indexes

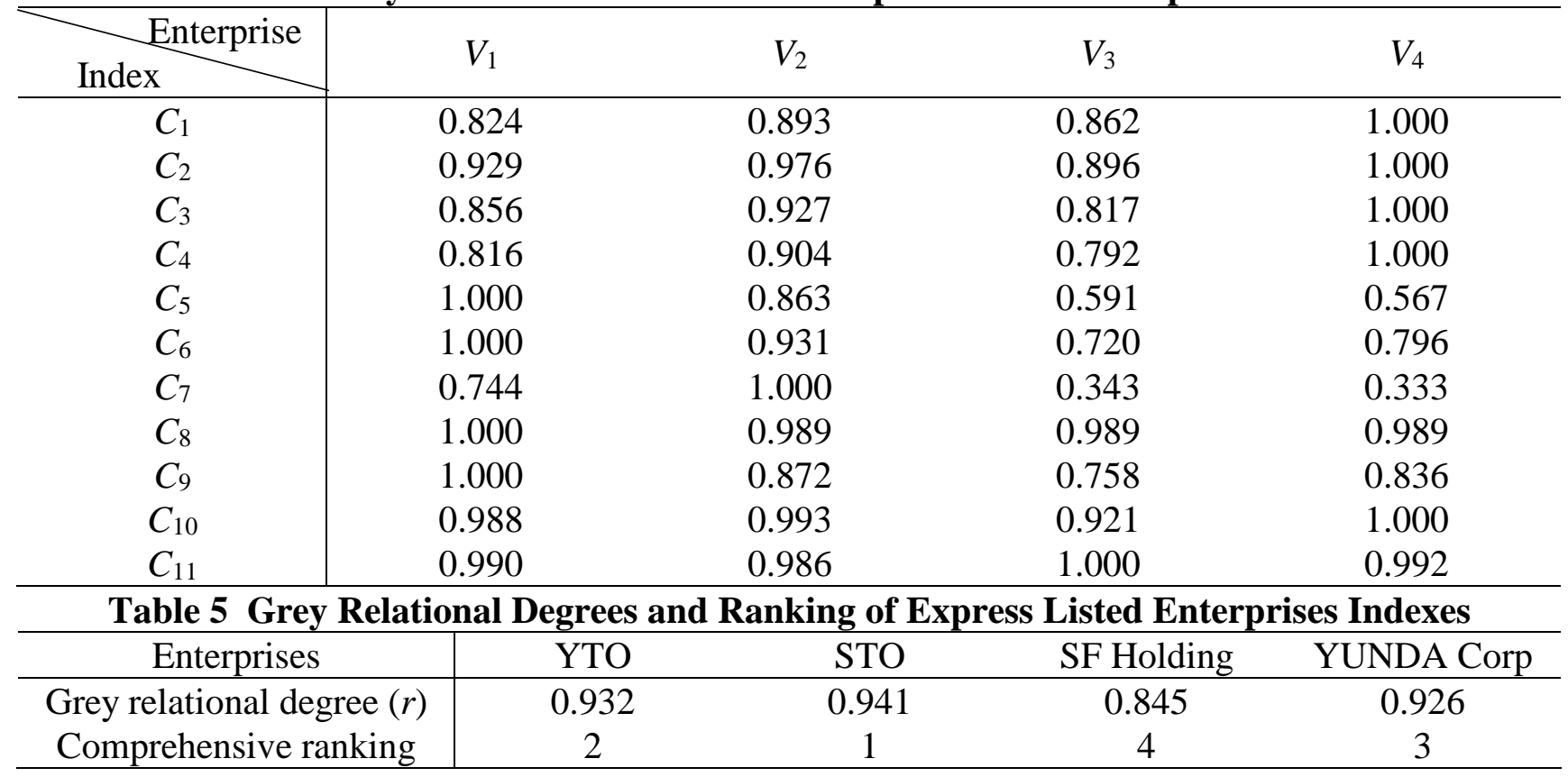

\section{Results and discussion}

We attempt to use different weights to recalculate and analyze the data, and find that express listed company performance ranking has not changed. So we obtain the ranking is credible. The comprehensive ranking of the four courier listed enterprises in 2016 is given in Table 5. The correlation between STO`s index and optimal index was the largest, which obviously showed that it 
had the best enterprise performance in the four express listed enterprises in 2016. In particular, in the case where only grey relational coefficient of current ratio $\left(C_{7}\right)$ was 1.000 , the company's relational degree $r$ reached the maximum value, which indicated that the comprehensive performance of STO was stronger.

The comprehensive ranking of YTO was second. Its grey relational coefficients of total asset turnover $\left(C_{5}\right)$, shareholders' equity ratio $\left(C_{6}\right)$, dividend financing ratio $\left(C_{8}\right)$ and dividend yield $\left(C_{9}\right)$ reached 1.000. To some extent, it showed that YTO had strong profitability, and outstanding ability of returns for shareholders with investment value in 2016.

YUNDA Corp ranked third, and its social performance was the best in all four express listed enterprises. But in its operational performance, grey relational coefficients of total asset turnover $\left(C_{5}\right)$ and current ratio $\left(C_{7}\right)$ were only $0.567,0.333$. Compared with other enterprises, YUNDA Corp did not achieve higher asset utilization in 2016, and the management and utilization of enterprise assets should be strengthened in the future development.

The comprehensive performance of SF Holding ranked last. Apart from index of return on equity $\left(C_{1}\right)$, total asset turnover $\left(C_{5}\right)$, current ratio $\left(C_{7}\right)$ and $\mathrm{R} \& \mathrm{D}$ investment accounted for operating income ratio $\left(C_{11}\right)$, the grey relational coefficients of other indexes were the lowest. It indicated that SF Holding company's operational performance and social performance was not highlight, and its innovative performance was outstanding. So the company's profitability and ability of returns for shareholders need to be further improved.

\section{Conclusions}

Express industry has a sustained rapid growth, but the decline in profit margins led to major enterprises into the bottleneck. And rapid financing has become a very important aspect of the operation strategy of express enterprises. Listing has become a way for express companies to pursue rapid financing. As a result, express enterprises have backdoor into stock market, in order to form a competitive advantage of capital. Related empirical research of express listed enterprises is still blank. Based on grey comprehensive evaluation method, we construct an evaluation index system of express listed enterprise performance with 1 target, 3 categories, 11 indicators including index grading and weighting. And it is found that grey relational analysis is effective and simple. The great advantages of this method are that it has no strict requirements on the sample size, does not require obeying any distribution. Meanwhile, it is clear and easy to analyze evaluation results. Express listed companies can be based on the ranking of grey relational degree $r$, to understand their own comprehensive performance in the express industry rankings. Meanwhile, listed companies can analyze advantages and disadvantages of enterprises by grey relational coefficient, and adjust and improve grey correlation coefficient of lower indicators, thereby enhancing overall enterprise performance level.

\section{Acknowledgements}

This work was financially supported by the Logistics Industry Planning Project of Wuhan Airport Economic Zone.

\section{References}

[1] Liu Jingzhi et al. Application of Benchmarking Method in Performance Evaluation of China 's Express Industry. [J]. China Storage \& Transport, 2006(5):106-107. (In Chinese)

[2] Liu Ying, Mao Cuiyun. Research on Performance Evaluation of Express Enterprise Based on BSC and Case Analysis. [J]. Logistics Technology, 2014(19):177-180. (In Chinese)

[3] Du Dong, et al. Modern Comprehensive Evaluation Method and Case Selection. [M]. Tsinghua University Press, 2008. (In Chinese)

[4] Ip W C, Hu B Q, Wong H, et al. Applications of grey relational method to river environment quality evaluation in China. [J]. Journal of Hydrology, 2009, 379(3):284-290. 